\title{
An Investigation into the Factors that Impact Successful Implementation of the Department of Higher Education and Training Skills Development at a College
}

\author{
Sello Tlabakwe \\ Department of Business Studies Management College of Southern Africa (MANCOSA) \\ Dr Roger Govender \\ Department of Business Studies Management College of Southern Africa (MANCOSA)
}

\begin{abstract}
The purpose of this study was to investigate a gap that exists between the Department of Higher Education and Training policy formulation and the institutional capacity at a South African college in implementation of skills development with a view to identifying capabilities and shortfalls. Conventional theories indicate that major inhibitors concerning the effectiveness of training and skills development in the contemporary public education system are often related to poor motivation and satisfaction of educators, macro-economic variables, and policy in the public education system and evaluation monitoring of the impact of skills development and training on educators' competencies. This research encompassed the positivist research paradigm using a quantitative research method. A survey was an appropriate quantitative research technique for accomplishing the data collection. Primary findings indicated that the effects of skills development training on the performance of the public educators are often latent in the improvement of educators' skills and competencies, the educators' job satisfaction and motivation, and the development of public educators. Future research can explore the effects of work-based learning on the effectiveness of the process of skills development.
\end{abstract}

Keywords: skills development, work-based learning

\section{INTRODUCTION}

The South African government has relied heavily on public Technical Vocational Education and Training (TVET) colleges in addressing the huge skills gap in the country. Despite consistent changes in policy and legislation relevant to the public TVET college sector in previous years, these colleges still struggle in implementing the relevant skills needed by the Department of Higher Education and Training. This study will investigate the factors that impact on the successful implementation of the Department of Higher Education and Training (DHET) strategy at a TVET college. There are 50 public TVET colleges countrywide, and for many years, the national government has prioritised public TVET colleges to promote quality skills development practices. The Department of Education (2001:5) stated that the main strategy of the DHET is "to mutate dysfunctional institutions into functional institutions that are capable of closing the gap in the skills deficit prevalent in South Africa".

\subsection{Problem Statement}

The purpose of this study is to investigate a gap that exists between the DHET policy formulation and institutional capacity at the college, with a view to identifying capabilities and shortfalls. The current issues or challenges faced by the college include concerns over inappropriate qualifications by academic and administration staff, lack of resources, teaching and learning inconsistencies and poor output of results. The DHET strategy adopted in January 2014 is outlined as follows:

- To reduce the skills bottlenecks and efficient and effective management of resources

- Improvement in the quality of education and teaching

- Reduce the cause of unemployment

- Differentiated and inclusive post-school system to fulfil social and economic participation goals

- Access aligned with enrolment, so that the ability to absorb students was not constrained 
There are a number of hindering factors making TVET colleges not to advance in certain areas. A bulk of a country's budget has been spent on education with TVET colleges taking a large part of it.

\subsection{Research Questions}

The research questions in the evaluation of:

- What are the impacts linked to the implementation of the Department of Higher Education and Training Skills Development at the TVET college?

- Which factors have been critical influencers for the successful implementation of the Department of Higher Education and Training Skills Development at the TVET college?

- Which factors are limiting the successful implementation of the Department of Higher Education and Training Skills Development at the TVET college?

- What recommendations can be provided to the management of the college on how to successfully implement the DHET strategy?

\subsection{Significance of the Study}

There has been little research undertaken in the past on TVET colleges, and no known study for this college in particular. The research, therefore, will be very important in determining the bottlenecks impacting negatively on the operations of the organisation. The research would be beneficial to a number of stakeholders. First, it will enable the DHET top management to understand the driving forces that prevent the successful implementation of their policies. Secondly, the management and employees of the college could identify what to do to ensure the successful implementation of the DHET strategy. Thirdly, the enrolled students at the college could be made aware of the shortfalls that exist in the institution that they depend upon to uplift their social status. Lastly, the adding to the currently available body of knowledge could benefit government and society at large, by gaining discernment of the challenges and bottlenecks facing the TVET colleges in general and this college in particular.

\section{LITERATURE REVIEW}

Training is a management activity which is undertaken to equip employees with relevant critical skills and competencies to render their performance more effective (Abderrahman and Giovanna, 2011:45). The purpose of a training programme is often a short-term based motive aimed at improving the performance of employees in the short-run. Critical types of training programmes often used in contemporary organisations encompass on-the-job and off-the-job methods. On-the-job methods involve training programmes in which employees are provided with practical opportunities to explore and acquire new skills by learning while accomplishing the required tasks (Abderrahman and Giovanna, 2011:45). Off-the-job training methods are often undertaken out of the required process of tasks accomplishment. Instead, as the name off-the-job training method suggests, off-the-job is usually accomplished through formal training programmes at a university or a college or during conferences, seminars and workshops (Abderrahman and Giovanna, 2011:45).

\subsection{Factors that Influence the Effectiveness of Skills Development and Training Programmes in Modern Organisations}

Literature interpretation implies that the influencers of the effectiveness of skills development and training programmes in the modern organisations are linked to management perceptions about skills development and training, the design of effective training and skills development programmes, the unique personal characteristics of the trainees, and the environment of skills development and training (Sheridan, 2007:63). The details of these influencers are examined as follows.

Management Perceptions about Skills Development and Training: Management perception about skills development and training is a critical predictor of the effectiveness of skills development and training programmes in contemporary public education systems (Lai, 2010:317). Management perception influences the overall management commitment to ensure that training and skills development programmes are not only well designed, but also tailored to the need to resolve the challenges that the school or a particular department is facing (Lai, 2010:317). Unfortunately, theories indicate that management perception about the value of training and skills development is one of the hurdles that still limit effectiveness of skills development and training programmes (Lai, 2010:317). 
Most managers in certain cases do not believe in the values of undertaking certain training and skills development programmes (Sheridan, 2007:63). Such a challenge limits the engagement of appropriate consultants, the design of appropriate skills development programmes and the allocation of appropriate resources to ensure that all the critical activities are successfully accomplished (Sheridan, 2007:63).

Design of Effective Training and Skills Development Programme: In most cases, most authors have tended to focus on highlighting the importance of effective design of training and skills development programmes (Martin, 2010:520). Unfortunately, empirical facts indicate that it has often turned out that with the necessary management commitment, the overall effectiveness of the design of relevant training and skills development programmes is usually positively affected (Martin, 2010:520). With demonstrable management commitment, the design of the skills development and training programme is often accomplished according to three critical steps that include; training needs analysis and identification of skills' gaps, the design of the skills development and training programmes, implementation and monitoring and evaluation of the success of the skills development and training programmes (Valcke, 2007:795).

Unique Personal Characteristics of the Trainees: Research on skills development and training indicates that there is a significant direct positive relationship between the effectiveness of the process of skills development and training and the unique personal characteristics of the learners (McGrath and Akooje, 2007:421). Personal characteristics of the learners such as age, gender, marital status, work roles and health are noted to play significant roles on the extent to which skills development and training programmes are most likely to influence the achievement of the desired effects (McGrath and Akooje, 2007:421). These unique personal characteristics of the learners influence selection decisions, learning abilities and the extent to which new knowledge and skills from training and skills development are able to diffuse among learners (McGrath and Akooje, 2007:421). Unique learners' personal characteristics also influence the extent to which learners are able to put the learnt skills into practice. In terms of age, prior empirical studies indicate that it is waste to commit resources on skills development and training programmes more on aged employees as compared to the younger and middle age ones (McGrath and Akooje, 2007:421). As compared to younger and middle-aged employees, older employees tend to grasp less fast not because they are less intelligent, but because in most cases at that age, they have already lost interest in acquiring new skills and knowledge (Vyas, 2010:149). Instead, they tend to be focusing on retirement which is not the case with the younger and middle-age employees. This affects their concentration and commitment during skills development and training and the extent to which they are able to apply the learnt skills in their new roles (Vyas, 2010:149).

Environment of Skills Development and Training:Ensuring the environment in which training and skills development is effective and appropriate is the other factor that influences the overall effectiveness of the process of training and skills development (Jacobson, LaLonde, and Sullivan 2011:66). Appropriate environment for skills development and training influences the overall process for the dissemination and acquisition of new skills and knowledge by the trainees (Jacobson et al. 2011:66). This implies that the selection of the location of the venue for training and skills development is a critical predictor of the effectiveness of the process of skills development training. Environments located in noisy or filthy neighbourhoods may tend to affect the overall perception of the trainees about the importance and values of such skills development and training programmes (Jacobson et al. 2011:66). Such perceptions can also affect the extent to which the trainees are able to have the necessary confidence in the system and acquire the necessary skills and competencies after the completion of training and skills development (Jacobson et al. 2011:66). The other factors in the environment that also affect the effectiveness of the process of skills development and training include the availability of equipment, training facilities, sound systems, lighting and the extent to which the trainees are intensely involved in the process of skills development and training (Kemple and Willner,2008:55).

\subsection{Inhibitors of the Effectiveness of Training and Skills Development in the Contemporary Public Education System}

Conventional theories indicate that the major inhibitors of the effectiveness of training and skills development in the contemporary public education system are often related to poor motivation and 
satisfaction of educators, macro-economic variables and policy in public education system and evaluation and monitoring of the impact of skills development and training on educators' competencies (Maguire, Freely, Clymer, Conway and Schwartz 2010:33;). The details of these inhibitors are evaluated as follows.

Poor Motivation and Satisfaction of Educators: Most authors argue that even if educators are equipped with necessary skills and competences, the improvement in their overall performance may only be minimal (Koedel and Julian, 2007:13). This is attributable to the fact that in addition to the necessary skills and competencies, the performance of the employees is also influenced by a combination of different sets of motivators. Some of these motivators are linked to the overall level of educators' satisfaction with their remuneration packages and work conditions (Koedel and Julian, 2007:13).

Macro-economic Variables and Policy in Public Education System: Macro-economic variables affect the effectiveness of training and skills development in the contemporary public education system on the basis that in the event of greater supply of jobs in the general economy, organisations may tend to lose funds on training and developing employees who later exit the organisation (Holzer, 2011:19). This leads to waste of funds and the extent to which an organisation is unable to utilise from its new pool of skilful and competent human resources. Although the situation is more controllable in private organisations, in public sector organisations that also include the contemporary public education system, it is often not easy to control the exodus of the employees after the completion of training and skills development programme (Holzer, 2011:19). Such a view is attributable to the fact that most public sector institutions pay quite lowly as compared to the private sector organisations. In this instance, most of the employees are often intending to exit (Feng, Figlio andSass 2010:29).

Evaluation and Monitoring of the Impact of Skills Development and Training on Educators'

Competencies: In most cases, the implementation of skills development and training programmes have not been accompanied by constant monitoring and evaluation to ensure that the educators who attended the training programmes have acquired the necessary skills (Adler and Davis, 2010:14). Such an approach limits the identification and correction of deviations that may be marring the effective application of the newly learnt skills and competencies.

\section{Research Methodology}

In the context of Kasim, Alexander and Hudson's (2010:19) interpretation, a research paradigm refers to a way of reasoning or a pattern of established practices that guide the process of inquiry over phenomena being investigated in social sciences. Hunter and Leahey (2008:290) highlights that over the years, fundamental differences have emerged among different research methodology theorists. In contrast to the views of anti-positivists or the proponents of inductive research paradigm, this research is conducted in the context of the positivist or deductive research paradigm.

\subsection{Research Design}

In contrast to the meaning of a research paradigm that deals with the wider philosophy and way of thinking underpinning the process of a particular research, the views of authors such as Van Ness, Fried and Gill (2011:293) imply that a research design narrows down the perspective that the research has undertaken into the prescription of the research methodologies, techniques and styles used in the accomplishment of the study. Johnson and Christensen (2008:49) highlight that the different types of research designs include; case study, causal, cohort, cross-sectional, descriptive, experimental, exploratory, historical, longitudinal, observational, philosophical and sequential research. This research is designed in accordance with the descriptive research design. Johnson and Christensen (2008:49) states that a descriptive research design is a research design that although provides methods and techniques that seek to explain things as they are like and describe relations, they do not predict relationships between variables or the direction of the relationship.

\subsection{Research Method}

It is the fundamental argument of Tashskkori and Teddlie (2010:49) that the selection of a research method that must be used in the study is not random, but significantly predicted by the overall research paradigm and the design that the study takes. They elaborate that in contrast to the research paradigm that explains the philosophy underpinning the study and the research design that provides a set of methods and techniques which are used in the study, a research method outlines the specific 
techniques that were used in the actual data collection process, analysis and interpretation. In this research, a quantitative research approach was used. Leedy and Ormrod (2010:119) reveal that the quantitative research method usually seeks summarised numerical responses.

\subsection{Research Population}

In a research process, Taylor (2007:119) posits that a research population refers to the larger units of analysis of the study. In this research, the research population refers to 840 people comprising of the principal of the college, deputy principals, campus managers, heads of departments both academic and support (administration), senior lecturers, junior lecturers and registered students. Fox, Hunn and Mathers (2009:33) posit that a sample connotes a percentage of the total target population which is used in the study. They argue that the determining of appropriate and valid sample size is critical for reaching valid and reliable conclusions in a quantitative research. In this endeavour, these authors therefore emphasize that it is important that appropriate methods are used.

\subsection{Sampling Methods}

Fox et al. (2009:33) argue that a consensus exists among research methodology theorists that depending on the research method used, the process of drawing the sample population from the larger population into the prescribed sample respondents can be accomplished using either probability or non-probability sampling. Whereas non-probability sampling is used in instances where a qualitative research method is used, they highlight that probability sampling is generally used in quantitative research methods. Considering that this research uses a quantitative research method, probability sampling is opted for in this study.

\subsection{Data Collection Method}

It is a common view among authors such as Moballeghi and Moghaddam (2008:125) and Diriwachter and Valsiner (2006:8) that a questionnaire is a commonly used data collection method in a quantitative research. A survey questionnaire was the principal research instrument used in this research.

\subsection{Pilot Testing}

Prior to pilot testing, a Cronbach Alpha's analysis was undertaken using the Statistical Programme for Social Sciences (SPSS) in order to assess the overall validity and reliability of the questionnaire. The purpose of pilot testing was also to examine the extent to which the respondents were able to easily understand the statements, sentences and wording in the questionnaires with limited intervention from the researcher.

\subsection{Data Analysis}

In the first instance, the obtained survey data was first checked to ensure that all the questions were answered. Thereafter, the data on the survey questionnaire was captured sequentially into the Statistical Programme for Social Sciences (SPSS) version 18.0. All these were accompanied by the measures for enhancing validity and reliability in a survey research.

\subsection{Validity and Reliability}

Fox et al. (2009:33) posit that validity refers to the extent to which the research measures what it is supposed to be measuring. Fox et al. (2009:33) reveal that construct validity is influenced by the overall flow of the study starting from the topic and research questions, literature review, sampling, the research instrument and methods of data analysis. In this research, there is significant consistency to reinforce the overall validity of the study for that the outline of the research questions is not only influenced the stipulation of issues that are relevant to the research topic, but also that the entire secondary research process was guided by the research questions. In a bid to further ensure that if the study was to be conducted, the same or similar results would still be obtained, the process of sampling ensured that all the population variances and differences were taken into consideration by applying scientific tests that guaranteed that the sample of 100 respondents obtained from a target population of 840 employees were representative. Other measures for ensuring reliability were also exercised during the design of the questionnaire. 


\subsection{Limitations of the Study}

Due to limited time available and scope of the study, it should be noted that the research process focused entirely on this particular college, rather than the entire country, for example. In addition, the demographic section was excluded from the questionnaire because forms were needed to be kept as short as possible and only asked what was intended for the analysis.

\subsection{Ethical Considerations}

Ethics in business research refers to norms or standards of behaviour that guide moral choices about the behaviour and relationships of the researcher with others (sample population) Wiid and Diggines, (2009). Wiid and Diggines (2009) prescribe that respondents used in research should be treated in an ethical manner. They advise that in order to treat respondents ethically, the researcher must make every effort to ensure that the respondent is not made to feel uncomfortable during the interview process and that the respondents should not be deceived as to the purpose of the interview. It is therefore essential to obtain the respondent's permission to conduct the interview and to hold all data collected from the respondents should be held in strict confidence (Wild and Diggines, 2009). In this study, ethical issues considered encompassed providing: a brief description of the nature of the study, a description of what participation would involve in terms of activities or duration, a statement indicating that participation is voluntary and can be terminated at any time without penalty, a list of any potential risk and/or discomfort which respondents may encounter, the guarantee that all responses would remain confidential and anonymous, the researcher's name, plus information about how the researcher can be contacted, an individual or office which the respondents could contact, should they have questions or concerns about the study, an offer to provide detailed information about the study, e.g. a summary of the findings upon the completion of the study, and a place for the respondents to sign and date the letter, indicating agreement to participate. The respondents' right to privacy was also observed by ensuring that all the obtained responses are strictly confidential. This was achieved by avoiding present information in a way in which others could easily discover how some or a particular respondent might have responded to certain questions or statements. Numbers were assigned to the participants to ensure that the data remains anonymous. Assurance was given to the respondents that they are free to discontinue their participation at any time without being required to offer an explanation. Participants' decisions and wishes to discontinue their participation were respected. Participants were also not put in situations where they would have been at risk of both physical and psychological harm as a result of their participation.

\section{RESULTS, DISCUSSION AND INTERPRETATION}

\subsection{Which Factors have been Critical Influencers for the Successful Implementation of the Department of Higher Education and Training Skills Development at the College?}

While guided by these conventional theoretical views on training and development and the first research question, the survey process in this section evaluated the critical influencers for the successful implementation of the Department of Higher Education and Training Skills Development at the college. The findings were as presented and discussed according to the following variables.

Commitment of the Government: The survey results imply that the commitment of the South African government seems to be a challenge. This is attributable to the fact that of the 100 surveyed respondents, $40 \%$ agreed that the government has demonstrated the necessary support and commitment towards the implementation of skills development strategies at the college compared to $37 \%$ of the respondents that have cumulatively disagreed with the statement. Such a view signifies that the overall commitment of the authorities and managers is critical for the successful accomplishment of the activities related to skills development. Some of the 100 surveyed respondents expressed concerns that the extent to which the government is fully committed and supportive is questionable. Such a view is attributable to the fact that of the 100 sample respondents, $23 \%$ were unsure, it is also noted that a significant number of the respondents $(37 \%)$ disagreed that the government had been providing the necessary commitment and support to ensure that the implementation of different skills development strategies at the TVET colleges is successful. The views of the $40 \%$ of the 100 surveyed respondents echo the opinions that the government having recognised the skills gap that the country faces, emphasised the need for the implementation of effective skills development strategies. 
Commitment of the Management of the College: As the government formulates policies on skills development and passes it onto the TVET colleges, the roles of these colleges are to ensure that such policies are successfully implemented. 37\% agreed that the management of the college has been instrumental in providing necessary commitment and support to ensure that all skills development strategies are effectively implemented. 33\% of the 100 surveyed respondents agreed as the $29 \%$ were unsure. This signifies that the overall commitment and support of the management of the college have often not been consistent to enhance the successful implementation of the skills development programmes.

Design of Effective Skills Development and Training Programmes: Of the 100 sampled respondents, $35 \%$ disagreed that effective skills development programmes are designed and implemented by the management of the college. The perception is that the college has not been effective in designing programmes intended to translate the government skills development strategies and policies into practice. When such a finding is corroborated with the findings on the previous variable, it can be noted that if the previous findings revealed that there is a challenge of management commitment at the college, it is unlikely to expect them to design and put in place effective skills development programmes.

Use of a Combination of Practical Work Related and Theoretical Methods: Of the 100 sampled respondents, a significant number of about $45 \%$ agreed that the management of the college has consistently put in measures to enhance the use of a combination of practical work related and theoretical training and skills development methods. This implies that the learners are provided with practical opportunities to experiment the new skills and competencies that they have learnt. However, on the extent to which a combination of practical work related and theoretical methods are used seems limited. While $45 \%$ of the respondents agreed, $31 \%$ disagreed that a combination of the work related practical and theoretical methods are used by the management of the college to enhance the effectiveness of the skills development and training programmes. Such a finding also seems to have been echoed by the $29 \%$ of the 100 sampled respondents who stated that they were unsure as to whether such methods are used.

Effective Monitoring and Evaluation of the Effectiveness of the Process of Skills Development: As compared to the survey results on the previous variables, most of the 100 sampled respondents highlighted that the Department of Higher Education and Training and the management of the college seem to face the challenge of monitoring and evaluation of the effectiveness of the process of skills development.Of the 100 sampled respondents, a significant number of the respondents of about $47 \%$ disagreed that effective monitoring and evaluation of the effectiveness of the process of skills development is taken place. However, the fact that $33 \%$ of the respondents were unsure and $47 \%$ disagreed does signify that monitoring and evaluation of the effectiveness of the skills development programme is not undertaken by the management of the college or the Department of Higher Education and Training. Such a view is based on the fact that $20 \%$ of the respondents agreed that effective monitoring and evaluation are undertaken to ensure that skills development and training programmes attain the intended objectives and goals.

\subsection{What are the Impacts Linked to the Implementation of the Department of Higher Education and Training Skills Development at the College?}

$37 \%$ of the 100 surveyed respondents disagree that there has an improvement of the skill levels and competencies of the population in Gauteng. Such a finding implies that perhaps the learners or trainees have not been able to demonstrate that they have learnt new skills or simply because the learning process is not effective.

Improvement of the Quality of Human Resources of the Country: Of the 100 surveyed respondents, $40 \%$ stated that they were unsure, and $23 \%$ of the 100 surveyed respondents agreed that the skills development and training programmes conducted by the college are contributing towards the improvement of the quality of human resources not only in the Gauteng province, but also in the entire country.

Contributes to Solving the Skills' Gap in Gauteng Province: With survey results in the previous variables indicating that there has been limited positive effects of the ongoing skills development and training programmes on the improvement of the skills and competencies of the country's human 
resource, it is not surprising that it that of the 100 surveyed respondents, most of them disagreed that the ongoing skills development and training programmes are contributing to solving the skills gap in the Gauteng province. $49 \%$ of the 100 sampled respondents disagreed that the skills development and training programmes being undertaken by the Department of Higher Education and Training are not contributing enough to the closing of the skills gap in the country. Such doubt about the overall effects of skills development and training on the closure of a country's skills gap is further echoed in the opinion of the $29 \%$ of the 100 sampled respondents who highlighted that they were unsure as to whether such a state of affairs has been attained. This could be attributable to the fact that there is either a challenge with the training methods or limited motivational strategies have been used to ensure that trainees complete their training programmes.

Improvement of the Employability of the Population in Gauteng: Of the 100 sampled respondents, $45 \%$ disagreed that the skills development and training programmes being conducted by the Department of Higher Education and Training has contributed towards the improvement of the employability of the population in the Gauteng Province. 25\% of the respondents were unsure, $30 \%$ of the 100 sampled respondents are noted to have agreed that to a greater extent the skills development and training programmes being conducted by the Department of Higher Education and Training have contributed towards improving the employability of most of the younger population in the Gauteng Province.

Improvement in the Development and Economic Growth of the Country: It is part of the fundamental argument in human resource theories that the improvement in the skills levels and competencies of the population influences the improvement in the development and economic growth of the country. Unfortunately, the survey results indicates that as compared to a majority of the 100 sampled respondents who disagreed, only $22 \%$ acknowledged that they feel that the skills development and training programmes undertaken by the Department of Higher Education and Training has contributed towards the improvement of the economic growth and development of the country. Such a finding implies that skills development and training programmes have not effectively contributed to the improvement of the skills levels and productivity of the population to instigate improvement of economic development and growth.

\subsection{Which Factors are Limiting the Successful Implementation of the Department of Higher Education and Training Skills Development at the College?}

In this third research question, the survey process examined the inhibitors of the successful implementation of the Department of Higher Education and Training Skills Development at the college. The findings were as presented and evaluated in the following subsections.

Poor Skills Levels of Educators and Trainers: Of the 100 sampled respondents, 58\% disagreed that poor skill levels of the educators and trainers is one of the factors limiting effective implementation of skills development and training programmes by the Department of Higher Education and Training. Such a finding implies that the trainers and educators at the college are well skilled to ensure effective transfer of the required technical skills and knowledge to the trainees. These views are further reinforced by the opinions of the $25 \%$ of the 100 sampled respondents who agreed that poor skills levels and competencies of the educators and trainers is a challenge undermining the overall effectiveness of the process of skills development and training.

Poor Commitment from Learners: Of the 100 sampled respondents, $23 \%$ of the respondents agreed that poor commitment of the learners is the other factor affecting the effectiveness of the skills development and training programmes at the college. Such a finding suggests that some of the learners seem less committed. This affects the process of skills transfer. Whereas personal factors such as the individual poverty levels of the trainees could also be affecting their concentration, 54\% disagreed that poor commitment among learners is one of the factors limiting the effectiveness of the skills development training programmes at the college. Such a view could be attributable to the fact that with the increasing level of unemployment, most of the trainees are increasingly beginning to note that technical education is the route to solving the ills of unemployment.

Lack of Employers' Confidence in TVET Colleges: As much as the findings indicate that learners' commitments to acquire new technical skills is not a challenge, the survey results imply that there is also a challenge linked to the employers' confidence on the quality of technical education provided by the TVET colleges. Such a view is attributable to the fact that of the 100 sampled respondents, $31 \%$ 
agreed that lack of employers' confidence in the quality of technical education provided by the TVET College is a challenge marring the effectiveness of the process of skills development. This implies that whenever trainees complete the relevant training and development programmes, they still tend to face the challenge of getting employment.

Poor Learning Environment and Lack of Essential Resources: Following the recognition of the challenge of skills gap and the need to improve technical skills in the country, the Department of Higher Education has been committing enormous resources towards the implementation of different skills development plans. Such a view explains why as compared to only a few percentage of the respondents who agreed, the survey results reveal that $73 \%$ of the 100 surveyed respondents disagreed that poor learning environment and lack of essential resources are part of the challenges undermining the effectiveness of the skills development and training programmes. However, it is important to note that although only $14 \%$ agreed that there is poor learning environment and lack of essential resource, they still provide a highlight of one of the critical challenges undermining the effectiveness of the skills development programmes.

Inappropriate Learning and Training Methods: Compared to the $14 \%$ of the 100 sampled respondents who agreed, $76 \%$ disagreed that inappropriate learning and training methods is not one of the challenges undermining effectiveness of the skills development and training programmes by the Department of Higher Education and Training. Nonetheless, it is important that attention is paid to the reasons why the $14 \%$ disagreed. Such a view is attributable to the fact that the learning and training methods used influence effectiveness of skills development and training programmes. In effect, constant monitoring and evaluation is critical.

\section{CONCLUSIONS AND RECOMMENDATIONS}

In line with the research objectives and questions, the key primary research findings of the study are as follows.

Influencers of the Successful Implementation of the Department of Higher Education and Training Skills Development at the College: The primary research indicated that most of the 100 sampled respondents agreed that the critical influencers of the effectiveness of skills development and training by the Department of Higher Education and Training are linked to the commitment of the government, commitment of the management of the college, design of effective skills development and training programmes, use of a combination of practical work related and theoretical methods, and effective monitoring and evaluation of the effectiveness of the process of skills development. The survey results imply that the commitment of the South African government seems not to be a challenge.

Impacts Linked to the Implementation of the Department of Higher Education and Training Skills Development at the College: When the percentages obtained on the variables in this construct are examined in the context of the mean scores and the standard deviations, it can be argued that the survey signifies that most of the 100 sampled respondents disagreed that the skills development and training programmes being undertaken by the college and the Department of Higher Education and Training have influenced the improvement of the skills levels and competencies of the population in Gauteng, improvement of the quality of human resources of the country, contributes to solving the skills' gap in Gauteng province, improvement of the employability of the population in Gauteng and the improvement in the development and economic growth of the country. A significant number of the 100 sampled respondents of about 33\% expressed that they were unsure as to whether the skills development and training programmes being undertaken by the college has contributed towards the improvement of the overall skills levels and competencies of the population in Gauteng province.

Inhibitors of the Successful Implementation of the Department of Higher Education and Training Skills Development at the College: Most of the respondents are noted to have disagreed that the inhibitors of the effectiveness of skills development and training at the College are linked to poor skills levels of educators' and trainers, poor commitment from learners, lack of employers' confidence in TVET colleges, poor learning environment and lack of essential resources and inappropriate learning and training methods. However, the fact that all the standard deviations for all the five variables in this construct indicate wider variability from the central mean implies that some 
of the respondents also agreed that the inhibitors of the effectiveness of skills development and training at the college are linked to poor skills levels of educators' and trainers, poor commitment from learners, lack of employers' confidence in TVET colleges, poor learning environment and lack of essential resources and inappropriate learning and training methods. 58\% disagreed that poor skills levels of the educators and trainers is one of the factors limiting effective implementation of skills development and training programmes by the Department of Higher Education and Training.

\subsection{Conclusions}

The management of the college and the Department of Higher Education and Training need to take the necessary measures to ensure that the factors that influence the skills development levels are effectively integrated as critical influencers of skills development and training. Such poor integration of all the critical success factors seems to have also affected the extent to which the ongoing skills development and training programmes are contributing towards the achievement of the desired objectives. Some respondents agreed that the inhibitors of the effectiveness of skills development and training at the college are linked to poor skills levels of educators' and trainers, poor commitment from learners, lack of employers' confidence in TVET colleges, poor learning environment and lack of essential resources and inappropriate learning and training methods.

Although some of the respondents are noted to have disagreed to the fact that all the standard deviations for all the five variables in this construct indicate wider variability from the central mean implies that some of the respondents also agreed that the inhibitors of the effectiveness of skills development and training at the college are linked to poor skill levels of educators' and trainers, poor commitment from learners, lack of employers' confidence in TVET colleges, poor learning environment and lack of essential resources and inappropriate learning and training methods. In the light of these findings, it is recommended that the management of the college must in conjunction with the Department of Higher Education and Training implement the following measures in order to improve the overall effectiveness of the implementation of different skills development programmes. These measures include: the design of an effective skills development and training programme, commitment of management and allocation of essential resources, creation of effective partners with the relevant key stakeholders, investment in training and development of the trainers, and monitoring and evaluation of the effectiveness of skills development and training programmes. Future research can explore the effects of work-based learning on the effectiveness of the process of skills development.

\subsection{Recommendations}

In the light of these findings, it is recommended that the management of the college must in conjunction with the Department of Higher Education and Training implement the following measures in order to improve the overall effectiveness of the implementation of different skills development programmes. These measures include:

Design of an Effective Skills Development and Training Programme: The design of an effective skills development and training programme signifies that the management of the college and the Department of Higher Education and Training must accomplish the critical activities that include training needs analysis and identification of skills' gaps, the design of the skills development and training programmes, implementation and monitoring and evaluation of the success of the skills development and training programmes.

Commitment of Management and Allocation of Essential Resources: The overall commitment of the managers of the college and the managers from the Department of Higher Education and Training is critical for ensuring that all the skills development and training programmes are implemented at the right time. This can be accomplished by ensuring that all the essential equipment and critical resources are offered to the stakeholders. Although the survey results indicated that training and skills development programmes are not affected by lack of equipment, it was noted that there is a challenge of lack of relevant equipment and resources. Hence, it is apparent that by providing the necessary financial resources, the management of the college and the Department of Higher Education and Training will be able to get rid of the challenges that still often undermine the effectiveness of the skills development and training programmes. 
Create Effective Partners with the Relevant Key Stakeholders: The management of the college and the Department of Higher Education and Training must consider creating effective partnerships and relationships with include the employers, government departments and other skills development and training colleges. Employers are important partners for the reason that they provide the platforms through which the trainees of different skills development and training programmes can have opportunities for apprenticeships and to explore how certain theoretical techniques and skills can be practically applied.

Investment in Training and Development of the Trainers: Investment in the training and development of the trainers is another critical intervention that the management of the college and the Department of Higher Education and Training can take to improve the skills levels and pool of skilful trainers. Such a view is derived from the fact that survey results indicated that there is a challenge of the skills levels of the trainers.

Monitoring and Evaluation of the Effectiveness of Skills Development and Training Programmes: Monitoring and evaluation of the effectiveness of the process of skills development and training will enable the management of the college and the Department of Higher Education and Training identify inhibitors and undertake measures for improving the overall effectiveness of the process skills development and training. Critical areas that must be observed during monitoring and evaluation include the availability of training equipment, the suitability of the training venue and environment, the competencies and skills levels of the trainers, and the extent to which the trainees are trying to implement and apply the new skills and competencies that they have learnt. The other areas that must be evaluated, include the efficiency of resource utilisation and the other intervening challenges that can limit the effectiveness of the process of skills development and training process.

\section{REFERENCES}

[1] Department of Education (2001) A new institutional landscape for public further education and training colleges: reform of South Africa's technical colleges. Pretoria: Department of Education.

[2] Abderrahman, H. and Giovanna, S. (2011) "Organizational training across cultures: variations in practices and attitudes". Journal of European Industrial Training, Vol. 35 Iss: 1, pp.45-70

[3] Sheridan, P. (2007) Human Resource Management. A guide for employers. Ireland: Oaktree Press.

[4] Lai W., H. (2010) Technical training in the MNCs in Malaysia: a case study analysis of the petrochemical industry.Journal of European Industrial Training, Vol. 34 Iss: 4, pp.317 - 343.

[5] Martin, H. (2010) Improving Training Impact through Effective follow-up: Techniques and their Application, Journal of Management Development, 29 (61), 520-534.

[6] Valcke, M. (2007) ICT teacher training: Evaluation of the curriculum and training approach in Flanders.Teaching and Teacher Education 23.6:795-808.

[7] McGrath, S. and Akooje, S. (2007) Education and skills for development in South Africa: Reflections on the accelerated and shared growth initiative for South Africa. International Journal of Education and Development, 27(4): 421-343.

[8] Vyas, L. (2010) Balancing outlook: assessment of public service training in Hong Kong by providers and clients. Public Personnel Management: 149-67Southern Africa: Oxford.

[9] Jacobson, L., S. LaLonde, R. and Sullivan, D. (2011) Policies to Reduce High-Tenured Displaced Workers' Earnings Losses through Retraining. Discussion Paper 2011-11, The Hamilton Project, Brookings Institution, Washington, DC.

[10] Kemple, J. and Willner, C. (2008) Career Academics: Long-Term Impacts on Labor Market Outcomes, Educational Attainment, and Transitions to Adulthood. New York: MDRC.

[11] Maguire, S. Freely, J. Clymer, C. Conway, M. and Schwartz, D (2010) Tuning Into Local Labor Markets: Findings from the Sectoral Employment Impact Study, Executive Summary. Public/ Private Ventures Publications, Philadelphia.

[12] Koedel, C., and Julian, R.B. (2007) Re-Examining the Role of Teacher Quality in the Educational Production Function. Working Paper \#2007-03. Nashville, Tenn.: National Center on Performance Initiatives. 
[13] Holzer, H.J. (2011) Raising Job Quality and Skills for American Workers: Creating MoreEffective Education and Workforce Development Systems in the States. Discussion Paper 201110, The Hamilton Project, Brookings Institution, Washington, DC.

[14] Feng, L., Figlio, D and Sass, T.(2010) School Accountability and Teacher Mobility. CALDER Working Paper No. 47, June. Washington DC: CALDER.

[15] Adler, J. and Davis, Z. (2010) Opening another black box: Researching mathematics for teaching in mathematics teacher education. Journal for Research in Mathematics Education.

[16] Kasim, R. Alexander, K. and Hudson, J. (2010) A choice of research strategy for identifying community-based action skill requirements in the process of delivering housing market renewal. Research Institute for the Built and Human Environment, University of Salford, UK.

[17] Hunter, L. and Leahey, E. (2008) Collaborative Research in Sociology: Trends and Contributing Factors. The American Sociologist. Vol: 39. pp 290 - 306. Springer US.

[18] Van Ness, P. H., Fried, T. R., and Gill, T. M. (2011) Mixed methods for the interpretation of longitudinal gerontologic data: Insights from philosophical hermeneutics. Journal of Mixed Methods Research. 5(4), 293-308.

[19] Johnson, B. and Christensen, L. (2008) Educational research: Quantitative, qualitative, and mixed approaches, Thousand Oaks, CA: Sage Publications.

[20] Tashakkori, A. and Teddlie, C. (2010)Sage handbook of mixed methods in social and behavioral research. $2^{\text {nd }}$ edition. Thousand Oaks, CA: Sage.

[21] Leedy, P.D. and Ormrod, J.E.(2010) Practical Research planning and design. 9th edition. New Jersey: Kevin M. Davis.

[22] Taylor, J. (2007) toward alternative forms of social work research: The case for naturalistic methods. Journal of Social Welfare. 4(2-3), 119-126.

[23] Fox, N. Hunn, A. and Mathers, N. (2009) Sampling and Sample Size Calculation. The NIHR Research Design Service for Yorkshire \& the Humber.

[24] Moballeghi, M. and Moghaddam, G., G. (2008) How Do We Measure The Use Of Scientific Journals? A Note on Research Methodologies. Volume: 76. Scientometrics (1): 125 - 133.

[25] Diriwachter, R. and Valsiner, J. (2006) Qualitative Developmental Research Methods in Their Historical and Epistemological Contexts. FQS. Vol 7, No. 1, Art. 8.

[26] Wild, J. and Diggines, C. (2009) Marketing Research. Lansdowne, Cape Town: Juta and Company Ltd. 